\title{
Effect of mindfulness and yoga on quality of life for elementary school students and teachers: results of a randomized controlled school-based study
}

This article was published in the following Dove Press journal:

Psychology Research and Behavior Management

\author{
Alessandra N Bazzano' \\ Christopher E Anderson ${ }^{2}$ \\ Chelsea Hylton ${ }^{3}$ \\ Jeanette Gustat ${ }^{2}$ \\ 'Department of Global Community \\ Health and Behavioral Sciences, Tulane \\ University School of Public Health and \\ Tropical Medicine, New Orleans, LA, \\ USA; ${ }^{2}$ Department of Epidemiology, \\ Tulane University School of Public \\ Health and Tropical Medicine, New \\ Orleans, LA, USA; ${ }^{3}$ Project Peaceful \\ Warriors, New Orleans, LA, USA
}

Objective: To assess the impact of a yoga curriculum in an elementary school on student quality of life, and to assess teacher and staff perception of potential barriers to, and benefits of, introducing yoga and mindfulness into the classroom.

Methods: A randomized controlled trial was utilized to assess the impact of a brief intervention on third-grade students who screened positive for symptoms of anxiety. Students were randomized to an intervention group of 20 students receiving small-group yoga/mindfulness activities for 8 weeks between October 2016 and February 2017, and a control group of 32 students receiving care as usual. The Brief Multidimensional Students' Life Satisfaction Scale-Peabody Treatment Progress Battery and the Pediatric Quality of Life Inventory (PedsQL) served as outcomes. Teachers were invited to participate in two professional development sessions about introducing yoga and mindfulness into the classroom, and completed a survey following each of the sessions. Results: In generalized estimating equation models adjusted for time, the yoga-based intervention was associated with a 14.17 unit increase in student emotional PedsQL ( $p$-value 0.001) and a 7.43 unit increase in psychosocial PedsQL ( $p$-value 0.01 ). Results were not attenuated by adjustment. Teachers and staff reported using yoga more frequently in the classroom following the second of two professional development sessions ( $p$-value $<0.05$ ). Perceived barriers to introducing yoga to the classroom were similar at two data collection time points, while perceived benefits remained high. Conclusion: The intervention was associated with a significant improvement in emotional and psychosocial quality of life in the intervention group when compared to the control group, suggesting that yoga/mindfulness interventions may improve symptoms of anxiety among students. Yoga/mindfulness activities may facilitate stress management among elementary school students and may be added as a complement to social and emotional learning activities.

Keywords: pediatrics, behavior modification, health related quality of life, anxiety, school health services, child health

\section{Introduction}

Educational reforms and the movement toward evaluation of school performance through student testing have amplified psychosocial demands on children ${ }^{1}$ and increasingly schools are seeking to improve social and emotional learning (SEL) programs, which reduce stress while addressing psychosocial development. Stress is an important and potentially malleable factor in the health of children, ${ }^{2}$ and school-aged children report having numerous stressors in their day-to-day experience, including such concerns as poor academic performance, peer exclusion and social pressure, being
Correspondence: Alessandra N Bazzano Department of Global Community Health and Behavioral Sciences, Tulane University School of Public Health and Tropical Medicine, New Orleans, LA, USA

Tel + I 5049882338

Email abazzano@tulane.edu 
bullied or teased, ${ }^{3}$ and homework. ${ }^{4,5}$ The stress caused by these day-to-day events may have an impact on children's health that lasts into the future ${ }^{6,7}$ leading to anxiety and other health concerns. Equipping children with coping strategies may allow them to better deal with these stressors and prevent impact on future health. ${ }^{8,9}$

More than two decades of evidence support the application of yoga and mindfulness practices for improving individual mental health and well-being, ${ }^{10}$ particularly for stress. ${ }^{11}$ Multiple systematic reviews provide evidence that yoga is effective at reducing anxiety and enhancing mood and well-being in adults. Two reviews looking at the efficacy of yoga interventions on stress management in adults found positive changes in psychological outcomes related to stress, but cited limitations including nonrandomized designs, small sample sizes, and nonstandardized yoga interventions. ${ }^{12,13}$ Encouraging results were also found in two reviews for yoga as a means of addressing anxiety and anxiety disorders in adults, ${ }^{14,15}$ but these identified similar limitations and the additional limitation of heterogeneous outcomes within individual studies. ${ }^{14}$ Yoga-based interventions were also found to have a suggestive positive effect on depressive disorders, although these results were subject to similar limitations as those for anxiety and stress in addition to the potential lack of feasibility of yoga interventions for adults with limited or impaired mobility. ${ }^{16}$

School-based yoga and mindfulness programs have become widespread over the last decade in the USA ${ }^{17}$ and are a promising approach to improving child and adolescent health and well-being. ${ }^{18,19}$ Relatively short mindfulness curricula have been demonstrated to improve teacher ratings of student classroom behavior, ${ }^{20}$ and a systematic review and meta-analysis of school-based mindfulness across different settings recently identified strong results in improving cognitive performance and resilience to stress among participating children. ${ }^{21}$

A recent small randomized controlled trial of mindfulness in school among fourth- and fifth-grade urban youth reported that the intervention was attractive to students, teachers, and school administrators and that it had a positive impact on problematic responses to stress including rumination, intrusive thoughts, and emotional arousal. ${ }^{22}$ Qualitative research has also identified perceived benefits to mindfulness and yoga programming including increased self-regulation, self-esteem, physical conditioning, academic performance, and stress reduction. ${ }^{23}$

A recent study of change in levels of stress among secondand third-grade students (as measured by salivary cortisol) found measurable changes following a short program of mindfulness yoga. ${ }^{24}$ The study authors reported the effects of a 10 -week classroom-based intervention. Students in the second grade, but not third grade, exhibited a decrease in cortisol level from before and after the intervention, while both groups of students showed significant decreases in cortisol level from before to after performance of a cognitive task. Additionally, teachers perceived some improvements in student behavior. ${ }^{24}$

Community partnerships with local organizations that deliver services to students are one way that schools may extend their ability to provide SEL-related activities, and may decrease the burden on teachers and staff to provide additional learning activities outside the required curriculum. ${ }^{25}$ These partnerships have been utilized to reduce problematic behaviors and to promote mental health and academic performance. ${ }^{26-29}$

The aim of the program evaluated in the present study was to improve the well-being of students, teachers, and staff by partnering an elementary school with a local social enterprise to incorporate dual yoga and mindfulness programming into the school's existing SEL program, with a specific focus on students who may be experiencing stress. Mindfulness and yoga were added to the school's existing empathy-based programming to provide additional targeted intervention for students identified as being in need of supplementary support. The study also sought to provide tools for teachers to use for all students in their classrooms on an ongoing basis. This study aimed to assess whether mindfulness and yoga instruction improved quality of life more than the usual care the school provided among students identified as having symptoms of anxiety.

\section{Methods}

A two-tiered study that included a randomized controlled trial of elementary school students receiving small-group yoga/ mindfulness sessions and two post-test only examinations of health-related quality of life for teachers and staff, after each of two professional development sessions, took place between October 2016 and February 2017 at one publicly funded elementary school in New Orleans, Louisiana, USA. Yoga and mindfulness sessions were provided through a community organization by an experienced children's yoga instructor who provided sessions to teachers, staff, and students.

\section{Study population}

The students included in this study were third graders who screened positive for symptoms of anxiety, using the validated Screen for Child Anxiety Related Emotional Disorders 
(SCARED) scale ${ }^{30}$ administered at the beginning of the 2016 academic year. Following the receipt of parental consent and student assent, students were randomized to an intervention group with 20 total students, which received the yoga and mindfulness intervention, or a control group with 32 students, which received care as usual, including counseling and other activities, led by the school social worker. All 52 students were given a baseline survey in which their basic demographics, prior experience with, and feelings about yoga and mindfulness, and quality of life were assessed.

Teachers and staff had two professional development sessions about including yoga instruction in the classroom. They were surveyed following each of the professional development sessions. These surveys assessed teaching experience, prior yoga experience and attitude toward yoga and mindfulness activities, experience with yoga in the classroom, and teacher's quality of life. Study authors performed secondary data analysis on data initially gathered by the elementary school during an internal pilot study of their new curricular programming, and provided only de-identified data to the authors. The protocol was submitted and approved for secondary data analysis by the Tulane University Institutional Review Board. Procedures related to consent and assent relate to the original data collection performed by the school staff and approved by leadership.

\section{Student intervention}

Students randomized to the intervention group participated in small-group yoga/mindfulness activities for 8 weeks led by a local social enterprise organization, using the validated Yoga Ed curriculum and materials. Yoga Ed is an evidence-based curriculum for utilizing yoga in the classroom and has been studied previously with children in schools. ${ }^{31}$ It includes the use of manualized and validated materials as the foundation of programs, which all meet national physical education and health standards, while also being uniquely designed to address core needs of educators and students.

Students randomized to the intervention received a total of 10 in-person, group sessions, each lasting 40 minutes, for 400 total minutes. The sessions were conducted in an empty classroom, before the instructional day began for the students. The session content included breathing exercises, guided relaxation, and several Vinyasa and Ashtanga poses appropriate for third graders.

\section{Randomization}

School staff randomized the 52 eligible students to three groups: a first intervention group of 10 students received yoga/mindfulness sessions in the fall, a second intervention group of 10 students received yoga/mindfulness sessions in the spring, and 32 students received care as usual. Randomization was accomplished using instructions and tools provided on the open source website randomizer.org, which requires a standard web browser connected to the Internet. ${ }^{32}$

\section{Teacher intervention}

An introductory professional development session on including yoga and mindfulness in the classroom was provided to teachers and school staff prior to the start of school year in the fall of 2016. All teachers and staff were invited to participate in an 1-hour professional development session to introduce a yoga and mindfulness curriculum that could be integrated into their classroom activities. Baseline information on teachers' previous experience with, perception of, and interest in yoga/ mindfulness, as well as quality of life and indicators of stress were obtained by the school for the evaluation.

All teachers were offered a second professional development session about using yoga/mindfulness in the classroom, building on the previous session, before the start of the second phase of the student intervention.

\section{Measurements}

\section{Students}

Data were collected from school students through three rounds. The first survey was given to students prior to randomization. The midpoint survey was given after the initial period of the yoga/mindfulness intervention had been completed. The final survey was given following the completion of the intervention by all participants randomized to the intervention group.

The Brief Multidimensional Students' Life Satisfaction Scale-Peabody Treatment Progress Battery version (BMSLSS-PTPB) was used to assess student satisfaction at baseline, midline, and endline surveys. ${ }^{33-35}$ The BMSLSSPTPB is a survey tool revised from the BMSLSS. Students were asked six questions about their satisfaction with five domains of their personal lives in addition to one question about general satisfaction with their lives. Responses ranged on a five-point scale from "very dissatisfied" to "very satisfied". The scores for the individual items were averaged together into the BMSLSS-PTPB total score, which represents overall life satisfaction, on a scale from 1 to 5 , with higher scores indicating greater satisfaction. The psychometric properties have previously been reported as robust. ${ }^{34}$

The Pediatric Quality of Life Inventory (PedsQL) was also used to assess student quality of life at the baseline, midline, 
and endline surveys. This tool is a series of 23 questions, split into physical, emotional, social, and school domains..$^{33,35}$ Respondents selected how frequently they experienced a given problem in the previous month on a five-point Likerttype scale, from "never" to "almost always". The responses were combined into six scores, one for each of the four domains, in addition to an overall score and a psychosocial score, which represented a combination of the domains of emotional, social, and school problems. Possible scores could range from 0 to 100 , with higher scores indicating lower average frequency of the problems in a given domain. The validity of this tool, and this method of scoring it, has previously been demonstrated to be high. ${ }^{36}$

\section{Teachers/staff}

Data collected from teachers included items from the Centers for Disease Control and Prevention's Healthy Days Measures, which is a tool for measuring health-related quality of life. ${ }^{37}$ Questions assessed the number of days in the prior month that the respondent would rate their mental health as suboptimal, their physical health as suboptimal, and the number of days on which their mental or physical health prevented them from completing their normal daily activities.

\section{Analysis}

The student intervention and control groups were compared at baseline. Intent-to-treat (ITT) analysis was performed, with all randomized subjects analyzed according to their assigned group regardless of adherence to the intervention. Differences in frequencies for categorical variables were assessed with Pearson's chi-square test, except where Fisher's exact test was indicated, and differences in means for continuous variables were assessed using $t$-tests. Change in PedsQL and BMSLSS-PTPB scores was computed at both the midline and endline surveys, and $t$-tests were performed to test for difference in mean change between intervention and control groups. Generalized estimating equations (GEEs) were used to model the repeated measurement of the continuous scores. These models allowed for assessing change in exposure status of the students when they received the intervention. Additionally, GEEs accommodate correlation between repeated measurements within individual students. ${ }^{38,39}$ The models were adjusted for survey time at which the outcome was assessed, homeroom teacher assignment, and student interest/ excitement for yoga at baseline. The $p$-values reported for GEE models are based on score tests, due to the anticonservative nature of Wald statistics with small sample sizes. ${ }^{40,41}$ Results with a $p$-value of $<0.05$ were considered statistically significant. SAS version 9.3 was used for all analyses (SAS Institute Inc., Cary, NC, USA).

\section{Results}

\section{Students}

A comparison of the intervention and control groups is provided in Table 1. There were no significant differences between intervention and control with regard to demographic traits, prior yoga experience, the PedsQL score, the PedsQL subscores, or BMSLSS-PTPB score. The intervention group was significantly more interested in yoga, with $95 \%$ rating themselves very or somewhat excited to participate, compared to only $59.38 \%$ among the controls at baseline $(p<0.01)$.

No differences existed in the baseline BMSLSS-PTPB or PedsQL scores between intervention and control groups (Table 2). Mean group scores for the psychosocial PedsQL and emotional PedsQL are shown in Figure 1. Groups 1 (Fall) and 2 (Spring) both received the intervention, while group 3 received care as usual. All three groups saw improvement in psychosocial PedsQL from baseline to the midline, but none saw significant improvement from baseline to endline. Both intervention groups 1 and 2 saw net improvement in emotional PedsQL from baseline to endline $(p<0.01)$, while there was no change in the control group.

At the midline survey, those in the intervention groups had a significantly larger mean improvement in emotional PedsQL score (17.39 for intervention compared to 0.75 for controls, $p$-value 0.005$)$. No other changes in score were significantly different between intervention and control, but physical, psychosocial, social, and overall PedsQL change was higher for the intervention group than for the control group. At the endline survey, a similar pattern was observed. The difference for emotional PedsQL achieved statistical significance, with an 18.27 unit increase in the intervention group from baseline compared to a 0.86 unit decrease in the control group from baseline ( $p$-value 0.009).

The results of the GEE models are shown in Table 3. In the model adjusted for the survey at which the outcome was assessed (Fall/Spring), the yoga-based intervention was associated with a 7.43 unit increase in student psychosocial PedsQL ( $p$-value 0.01 ), and this association was only slightly attenuated and remained statistically significant following adjustment for homeroom assignment and baseline interest in yoga ( $p$-value 0.02 ). Likewise, the intervention was associated with a 14.17 unit increase in student emotional PedsQL in the model adjusted for the survey at which the outcome was assessed ( $p$-value 0.001). This was not attenuated by 
Table I Baseline demographic characteristics, yoga experience, expectations of yoga, and quality-of-life indices of third-grade students assigned to yoga/mindfulness intervention and students assigned to standard care

\begin{tabular}{|c|c|c|c|}
\hline Characteristics & Intervention $(\mathbf{N}=\mathbf{2 0})$ & Control $(\mathrm{N}=32)$ & $p$-value \\
\hline Male, $\mathrm{n}(\%)$ & $10(50.0)$ & $17(53.1)$ & 1.0 \\
\hline White, n (\%) & $12(63.2)$ & $13(46.4)$ & 0.79 \\
\hline Any previous yoga, n (\%) & $13(65.0)$ & $18(56.3)$ & 0.54 \\
\hline Five or more previous yoga classes, n (\%) & $7(35.0)$ & $13(40.6)$ & 0.69 \\
\hline Level of interest/excitement for yoga, $n(\%)$ & & & 0.01 \\
\hline Very & $8(40.0)$ & $10(31.25)$ & \\
\hline Somewhat & II (55.0) & $9(28.13)$ & \\
\hline Do you think yoga can help you feel calm, n (\%) & & & 0.52 \\
\hline Yes, a lot & II (55.0) & $12(37.5)$ & \\
\hline Yes, a little & $3(15.0)$ & $8(25.0)$ & \\
\hline Maybe & $6(30.0)$ & $10(31.25)$ & \\
\hline BMSLSS-PTPB, mean \pm SD & $4.07 \pm 0.86$ & $3.97 \pm 0.61$ & 0.61 \\
\hline PedsQL: overall, mean \pm SD & $69.17 \pm 21.10$ & $68.13 \pm 12.93$ & 0.84 \\
\hline PedsQL: physical, mean \pm SD & $73.59 \pm 23.74$ & $75.27 \pm 15.82$ & 0.76 \\
\hline PedsQL: psychosocial, mean \pm SD & $66.73 \pm 21.98$ & $64.38 \pm 14.60$ & 0.65 \\
\hline PedsQL: emotional, mean $\pm S D$ & $51.98 \pm 24.11$ & $55.36 \pm 22.43$ & 0.61 \\
\hline PedsQL: social, mean \pm SD & $78.75 \pm 21.45$ & $71.77 \pm 17.68$ & 0.21 \\
\hline PedsQL: school, mean \pm SD & $68.75 \pm 27.04$ & $66.48 \pm 16.54$ & 0.71 \\
\hline
\end{tabular}

Abbreviations: BMSLSS-PTPB, Brief Multidimensional Students' Life Satisfaction Scale-Peabody Treatment Progress Battery version; PedsQL, Pediatric Quality of Life Inventory.

Table 2 Changes in student BMSLSS-PTPB and PedsQL scores in the intervention and control groups from baseline, presented as mean $\pm S D$, for intervention and control

\begin{tabular}{|c|c|c|c|c|c|c|c|c|}
\hline \multirow[t]{2}{*}{ Characteristics } & \multicolumn{2}{|c|}{$\begin{array}{l}\text { Baseline student } \\
\text { scores }\end{array}$} & \multicolumn{3}{|c|}{$\begin{array}{l}\text { Midline change in student } \\
\text { scores from baseline }\end{array}$} & \multicolumn{3}{|c|}{$\begin{array}{l}\text { Endline change in student } \\
\text { scores from baseline }\end{array}$} \\
\hline & $\begin{array}{l}\text { Intervention } \\
(\mathrm{n}=\mathbf{2 0})\end{array}$ & $\begin{array}{l}\text { Control } \\
(n=32)\end{array}$ & $\begin{array}{l}\text { Intervention } \\
(\mathrm{n}=\mathbf{2 0})\end{array}$ & $\begin{array}{l}\text { Control } \\
(n=32)\end{array}$ & $\begin{array}{l}P \text { for } \\
\text { difference }\end{array}$ & $\begin{array}{l}\text { Intervention } \\
(\mathrm{n}=20)\end{array}$ & $\begin{array}{l}\text { Control } \\
(n=32)\end{array}$ & $\begin{array}{l}P \text { for } \\
\text { difference }\end{array}$ \\
\hline BMSLSS-PTPB & $4.07 \pm 0.86$ & $3.97 \pm 0.61$ & $0.17 \pm 0.70$ & $0.19 \pm 0.43$ & 0.916 & $0.09 \pm 0.68$ & $0.13 \pm 0.53$ & 0.833 \\
\hline PedsQL: overall & $69.17 \pm 21.10$ & $68.13 \pm 12.93$ & $7.4 I \pm 17.82$ & $2.15 \pm 8.04$ & 0.227 & $7.13 \pm 20.37$ & $0.82 \pm 13.44$ & 0.230 \\
\hline PedsQL: physical & $73.59 \pm 23.74$ & $75.27 \pm 15.82$ & $4.38 \pm 20.90$ & $0.70 \pm 9.89$ & 0.469 & $3.13 \pm|5.5|$ & $0.92 \pm 13.04$ & 0.589 \\
\hline PedsQL: psychosocial & $66.73 \pm 21.98$ & $64.38 \pm 14.60$ & $8.86 \pm 18.11$ & $2.86 \pm 10.35$ & 0.190 & $9.32 \pm 25.06$ & $0.43 \pm 16.11$ & 0.129 \\
\hline PedsQL: emotional & $51.98 \pm 24.11$ & $55.36 \pm 22.43$ & $|7.39 \pm 23.0|$ & $0.75 \pm 16.66$ & 0.005 & $18.27 \pm 27.96$ & $-0.86 \pm 21.00$ & 0.009 \\
\hline PedsQL: social & $78.75 \pm 21.45$ & $71.77 \pm 17.68$ & $6.50 \pm 23.18$ & $3.67 \pm 13.19$ & 0.624 & $1.50 \pm 28.93$ & $-3.00 \pm 22.54$ & 0.540 \\
\hline PedsQL: school & $68.75 \pm 27.04$ & $66.48 \pm 16.54$ & $3.67 \pm \mid 7.61$ & $3.31 \pm 14.48$ & 0.937 & $8.8 \mathrm{I} \pm 26.24$ & $2.54 \pm 15.89$ & 0.345 \\
\hline
\end{tabular}

Note: Data are presented as mean \pm SD.

Abbreviations: BMSLSS-PTPB, Brief Multidimensional Students' Life Satisfaction Scale-Peabody Treatment Progress Battery version; PedsQL, Pediatric Quality of Life Inventory.

adjustment for homeroom assignment and baseline interest in yoga. Results were not statistically significant for the other outcomes, but in models adjusted only for survey at which the outcome was assessed, the yoga intervention was associated with nonsignificant increases in overall PedsQL and social PedsQL.

\section{Teachers}

The teachers were also surveyed following two professional development sessions on yoga and mindfulness techniques in the classroom held at the beginning and end of the school year (Table 4). Teachers were asked about a number of potential barriers to implementing yoga in the classroom, as well ways yoga might help if introduced into the classroom.
The results from the two professional development sessions were similar, with teachers and staff on average identifying nearly six ways yoga may help in the classroom including helping students self-regulate, helping students be calm, helping the teacher be calm, or improving the classroom climate. Teachers on average identified fewer than two potential barriers to introducing yoga such as being too busy with academic requirements or lack of self-confidence using yoga techniques. The number of times per week the teachers reported using yoga in the classroom increased from 1.28 to 2.39 ( $p$-value 0.03 ) between the first and second professional development sessions, while the mean number of times per day the teachers reported using yoga in the classroom increased from 0.76 to 1.63 times per day ( $p$-value 
PedsQL psychosocial

90

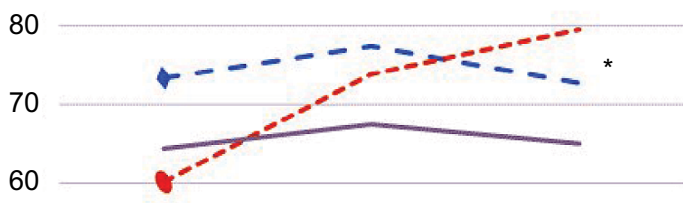

50

40

30

$\begin{array}{ccc}\text { Data } & \text { Data } & \text { Data } \\ \text { collection } 1 & \text { collection } 2 & \text { collection } 3\end{array}$

PedsQL Emotional

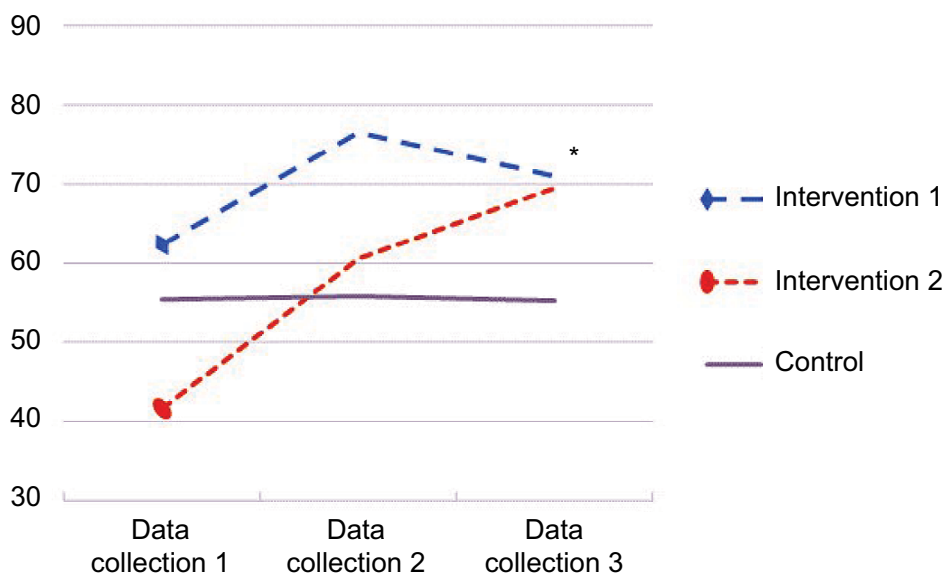

Figure I Mean student PedsQL psychosocial and emotional scores in intervention group I (fall), intervention group 2 (spring), and control groups from baseline, midline, and endline surveys.

Notes: Statistically significant differences between intervention and control groups were observed for psychosocial PedsQL at survey 3 ( $p$-value 0.03 ) and for emotional PedsQL at survey 3 ( $p$-value 0.02).

Abbreviation: PedsQL, Pediatric Quality of Life Inventory.

Table 3 Parameter estimates ${ }^{a}$ for small-group yoga intervention on student BMSLSS-PTPB and PedsQL scores

\begin{tabular}{|c|c|c|c|c|c|c|}
\hline \multirow[t]{2}{*}{ Student outcome } & \multicolumn{2}{|l|}{ Model I } & \multicolumn{2}{|l|}{ Model 2} & \multicolumn{2}{|l|}{ Model 3} \\
\hline & Estimate & $p$-value* & Estimate & $p$-value* & Estimate & p-value* \\
\hline BMSLSS-PTPB & 0.004 & 0.98 & -0.01 & 0.96 & -0.01 & 0.93 \\
\hline PedsQL: overall & 4.44 & 0.08 & 4.44 & 0.08 & 4.27 & 0.09 \\
\hline PedsQL: physical & 0.67 & 0.81 & 0.89 & 0.76 & 0.92 & 0.76 \\
\hline PedsQL: psychosocial & 7.43 & 0.01 & 7.60 & 0.01 & 7.25 & 0.02 \\
\hline PedsQL: emotional & 14.17 & 0.001 & 14.35 & $<0.001$ & 14.24 & $<0.001$ \\
\hline PedsQL: social & 5.65 & 0.11 & 5.58 & 0.12 & 4.77 & 0.17 \\
\hline PedsQL: school & 3.61 & 0.31 & 3.81 & 0.29 & 3.59 & 0.32 \\
\hline
\end{tabular}

Notes: aparameter estimates from generalized estimating equation models. Model I, adjusted for survey at which the outcome was assessed. Model 2, adjusted for survey at which the outcome was assessed and student homeroom assignment. Model 3, adjusted for survey at which the outcome was assessed, student homeroom assignment, and baseline interest in yoga. *The $p$-values presented for the generalized estimating equations parameter estimates are type 3-score-test-based $p$-values. Bold values indicate significance.

Abbreviations: BMSLSS-PTPB, Brief Multidimensional Students' Life Satisfaction Scale-Peabody Treatment Progress Battery version; PedsQL, Pediatric Quality of Life Inventory.

0.005). The self-reported physical health of teachers was significantly worse at the second professional development session (4.15 days in the past month where physical health was not good at the second session compared to 1.08 at the first session, $p$-value 0.01 ). Other metrics of teacher health were not significantly different between the two professional development sessions.

Teachers reported feeling that yoga could be very helpful, with seven of the nine potential benefits exceeding 50\% affirmative responses. The barriers most frequently cited as hindering the introduction of yoga into the classroom include being too busy with academic requirements, teacher's lack of self-confidence using the techniques, and student resistance.

\section{Discussion}

The data presented indicate that students did benefit from this relatively short intervention, and that teachers and staff derived benefit as well. The students who received the intervention demonstrated significantly greater improvement in psychosocial and emotional quality of life compared with their peers who received standard care. Teachers reported many potential benefits of using yoga in the classroom and also reported using yoga in the classroom more days each week and more times each day following the student intervention.

Students' psychosocial and emotional scores increased as a result of participating in small-group yoga and mindfulness activities at school, and previous studies have not used the specific measures applied in this study. These findings are important because they provide educators with a set of tools that may benefit students dealing with emotional or psychosocial issues. The benefits highlighted in this study lend support to results from prior studies where mindfulness and yoga curricula decreased negative emotional responses 
Table 4 Teacher responses to survey completed at the end of two professional development sessions, one before and one after the student intervention

\begin{tabular}{|c|c|c|c|}
\hline Teacher response & $\begin{array}{l}\text { Session I } \\
(N=25)\end{array}$ & $\begin{array}{l}\text { Session } 2 \\
(N=4 I)\end{array}$ & $p$-value \\
\hline \multicolumn{4}{|l|}{ Barriers to introducing yoga in classroom, $\mathrm{n}(\%)$} \\
\hline Too busy with academic requirements & $14(56)$ & $22(53.66)$ & \\
\hline Self-confidence using techniques & $5(20)$ & $13(3|.7|)$ & \\
\hline Student resistance & $3(12)$ & $10(24.39)$ & \\
\hline Lack of training resources & $15(60)$ & $8(19.51)$ & \\
\hline Do not have personal experience with it & $6(24)$ & $6(14.63)$ & \\
\hline Do not feel it is helpful & $0(0)$ & I (2.44) & \\
\hline Not a secular practice & I (4) & $0(0)$ & \\
\hline Too difficult & $0(0)$ & $0(0)$ & \\
\hline \multicolumn{4}{|l|}{ Ways yoga may help in classroom, $\mathrm{n}(\%)$} \\
\hline Helping students be calm & $17(68)$ & $36(87.8)$ & \\
\hline Student self-regulation & $20(80)$ & $30(73.17)$ & \\
\hline Helping me to be calm & $16(64)$ & $29(70.73)$ & \\
\hline Increasing ability to focus & $20(80)$ & $29(70.73)$ & \\
\hline Improving the climate of the classroom & $12(48)$ & $27(65.85)$ & \\
\hline Smooth transitions & $13(52)$ & $26(63.4 I)$ & \\
\hline Classroom management & $21(84)$ & $22(53.66)$ & \\
\hline Boost student learning and achievement & $17(68)$ & $20(48.78)$ & \\
\hline Student academic performance & $12(48)$ & $19(46.34)$ & \\
\hline Weekly times yoga used in class, mean $\pm S D$ & $1.28 \pm 1.76$ & $2.39 \pm 1.97$ & 0.03 \\
\hline Daily times yoga used in class, mean \pm SD & $0.76 \pm 1.05$ & $1.63 \pm 1.24$ & 0.005 \\
\hline Number of barriers reported, mean $\pm S D$ & $1.76 \pm 1.09$ & $1.46 \pm 1.05$ & 0.28 \\
\hline Number of potential benefits reported, mean $\pm S D$ & $5.76 \pm 2.89$ & $5.8 I \pm 2.84$ & 0.95 \\
\hline \multicolumn{4}{|l|}{ Number of days in last 30 days, mean $\pm S D$} \\
\hline Physical health not good & $1.08 \pm 2.14$ & $4.15 \pm 6.98$ & 0.01 \\
\hline Mental health not good & $6.04 \pm 6.03$ & $6.18 \pm 7.03$ & 0.94 \\
\hline Bad health prevented usual activities & $1.76 \pm 2.59$ & $1.80 \pm 3.21$ & 0.96 \\
\hline Stress scale, mean $\pm S D$ & $8.80 \pm 3.84$ & $7.90 \pm 4.33$ & 0.40 \\
\hline
\end{tabular}

and stress, and improved self-esteem in students, ${ }^{22,23}$ and benefited adults suffering from anxiety and depression. ${ }^{14-16}$ The improvement in psychosocial and emotional quality of life may reflect similar reductions in anxiety and stress among the third graders included in this study.

A recent study explored children's perceptions of stress and the impact of a yoga intervention on decreasing that stress. ${ }^{42}$ Researchers employed qualitative methods to understand the experiences of urban students who attended the 16-week program, which included yoga and mindfulness. Students identified changes around domains of anger, aggressive behavior, and interpersonal stressors. ${ }^{42} \mathrm{~A}$ companion study conducted by the same authors explored teacher experiences alongside the qualitative data collected from fifth- and sixth-grade participants in the program. Both students and teachers reported realistic and positive expectations related to the program..$^{43}$

Studies that only substitute yoga for other types of physical activities as part of a physical education program may not adequately incorporate behavioral approaches that support children to adopt the practice in their day-to-day lives. One study found no benefit to yoga when compared to physical education class for reducing stress. ${ }^{44}$ The lack of significant differences may be due to that yoga intervention failing to focus on stress management and/or the stressor tasks not adequately capturing attenuation of stressor response, where physiologic endpoints were used to assess stress reactivity, as opposed to quality-of-life measures, as used in the present study.

In a study conducted among fourth- and fifth-grade girls, White reported that mindfulness intervention was associated with a significant increase in appraisal of stress score. ${ }^{2}$ White's results were unanticipated, and contrasted with the results of the present study, may suggest some design issues. The prior study was composed of girls drawn from two schools, and randomization was performed at the school level, precluding any ability of the researcher to distinguish school-related changes in student stress from changes due to the intervention. Additionally, White's study excluded students with prior formal yoga experience or a need for 
special educational support. In effect, the study was a clusterrandomized trial with a sample size of two (two schools), composed of school-aged white females without baseline medical or psychological diagnoses. The present study randomized individual students, included male and female children of diverse racial backgrounds, and the students were all determined to be at high risk for anxiety at baseline.

The present study utilized small-group yoga classes that were adapted to the needs of the individual students and their unique age group and environment. Hagen and Nayar presented a recent compilation of the impact of yoga on children's mental well-being and note that yoga instruction should be tailored to the audience, multidisciplinary, and based on children's needs while retaining a playful tone. ${ }^{45}$

This study has several limitations. Although the sample size was limited, with only 20 subjects in the intervention group, significant differences were identified between intervention and comparison groups. Additionally, the two intervention groups received their intervention at different times of the year. Student perception of their own quality of life may be subject to change during the course of a given school year, so the baseline on which the intervention was administered was not necessarily the same for both intervention groups. The intervention evaluated combined yoga and mindfulness, and this study is, therefore, unable to identify whether one or both of these components was responsible for the improvements in psychosocial and emotional well-being.

This study has several strengths that deserve emphasis. The first is that the small-group yoga and mindfulness intervention was targeted to the needs of the children who were participating, and likewise, the training for teachers was tailored to educators of children in the local context. The subjects were randomly assigned to either the intervention or control groups, avoiding the self-selection of the exposure. The ITT analysis preserved the benefits of the randomization. The use of a previously studied yoga education curriculum allows the results of this study to be compared with others previously reported. Students' quality of life was assessed using previously validated instruments designed for use in children. Finally, the data collected from teachers and staff will facilitate future research by helping ensure that it is tailored to address the concerns and suggestions of the educators.

This study demonstrated that a yoga-based intervention in an educational setting can improve emotional and psychosocial well-being among third-grade students who screen positive for symptoms of anxiety. Further research should be conducted with diverse and larger populations, including additional age groups, to determine whether this improvement of quality of life remains, and whether the effects of yoga are applicable to a more general population of students. Yoga and mindfulness curricula may provide children at risk of anxiety with a skill enabling them to improve their psychosocial and emotional quality of life. These coping skills, when provided in the school environment, may assist students achieve optimum physical and mental health.

\section{Acknowledgment}

The authors are grateful to Monique Kerrigan, Janine Murry, Jan Rice, and Sheila Nelson for their contributions; and to the Tulane University Center for Public Service, and Taylor Center for Social Innovation and Design Thinking for support.

\section{Disclosure}

The authors report no conflicts of interest in this work.

\section{References}

1. Skybo T, Buck J. Stress and coping responses to proficiency testing in school-age children. Pediatr Nurs. 2007;33(5):410, 413-418.

2. White LS. Reducing stress in school-age girls through mindful yoga. J Pediatr Health Care. 2012;26(1):45-56.

3. Horowitz JA, Vessey JA, Carlson KL, et al. Teasing and bullying experiences of middle school students. J Am Psychiatr Nurses Assoc. 2004;10(4):165-172.

4. Ryan-Wenger NA, Sharrer VW, Campbell KK. Changes in children's stressors over the past 30 years. Pediatr Nurs. 2005;31(4):282-288, 291.

5. Sharrer VW, Ryan-Wenger NA. School-age children's self-reported stress symptoms. Pediatr Nurs. 2002;28(1):21.

6. Carter JS, Garber J, Ciesla JA, Cole DA. Modeling relations between hassles and internalizing and externalizing symptoms in adolescents: a four-year prospective study. J Abnorm Psychol. 2006;115(3): 428-442.

7. Compas BE, Malcarne VL, Fondacaro KM. Coping with stressful events in older children and young adolescents. J Consult Clin Psychol. 1988;56(3):405-411.

8. Grant KE, Compas BE, Thurm AE, et al. Stressors and child and adolescent psychopathology: evidence of moderating and mediating effects. Clin Psychol Rev. 2006;26(3):257-283.

9. Rutter M. Implications of resilience concepts for scientific understanding. Ann N Y Acad Sci. 2006;1094(1):1-12.

10. Gotink RA, Chu P, Busschbach JJ, Benson H, Fricchione GL, Hunink MG. Standardised mindfulness-based interventions in healthcare: an overview of systematic reviews and meta-analyses of RCTs. PLoS One. 2015;10(4):e0124344

11. Kabat-Zinn J, Massion AO, Kristeller J, et al. Effectiveness of a meditation-based stress reduction program in the treatment of anxiety disorders. Am J Psychiatry. 1992;149(7):936-943.

12. Chong CS, Tsunaka M, Tsang HW, Chan EP, Cheung WM. Effects of yoga on stress management in healthy adults: a systematic review. Altern Ther Health Med. 2011;17(1):32-38.

13. Sharma M. Yoga as an alternative and complementary approach for stress management: a systematic review. J Evid Based Complementary Altern Med. 2014;19(1):59-67.

14. Kirkwood G, Rampes H, Tuffrey V, Richardson J, Pilkington K. Yoga for anxiety: a systematic review of the research evidence. Br J Sports Med. 2005;39(12):884-891; discussion 891.

15. Li AW, Goldsmith CA. The effects of yoga on anxiety and stress. Altern Med Rev. 2012;17(1):21-35. 
16. Pilkington K, Kirkwood G, Rampes H, Richardson J. Yoga for depression: the research evidence. J Affect Disord. 2005;89(1-3):13-24.

17. Butzer B, Ebert M, Telles S, Khalsa SB. School-based yoga programs in the United States: a survey. Adv Mind Body Med. 2015;29(4):18-26.

18. Khalsa SB, Butzer B. Yoga in school settings: a research review. Ann NY Acad Sci. 2016;1373(1):45-55.

19. Ferreira-Vorkapic C, Feitoza JM, Marchioro M, Simoes J, Kozasa E, Telles S. Are there benefits from teaching yoga at schools? A systematic review of randomized control trials of yoga-based interventions. Evid Based Complement Alternat Med. 2015;2015:345835.

20. Black DS, Fernando R. Mindfulness training and classroom behavior among lower-income and ethnic minority elementary school children. J Child Fam Stud. 2014;23(7):1242-1246.

21. Zenner C, Herrnleben-Kurz S, Walach H. Mindfulness-based interventions in schools-a systematic review and meta-analysis. Front Psychol. 2014;5:603.

22. Mendelson T, Greenberg MT, Dariotis JK, Gould LF, Rhoades BL, Leaf PJ. Feasibility and preliminary outcomes of a school-based mindfulness intervention for urban youth. J Abnorm Child Psychol. 2010;38(7):985-994.

23. Wang D, Hagins M. Perceived benefits of yoga among urban school students: a qualitative analysis. Evid Based Complement Alternat Med. 2016;2016:8725654.

24. Butzer B, Day D, Potts A, et al. Effects of a classroom-based yoga intervention on cortisol and behavior in second- and third-grade students: a pilot study. JEvid Based Complementary Altern Med. 2015;20(1):41-49.

25. Sanders MG. Community involvement in schools. Educ Urban Soc. 2003;35(2):161-180

26. Greenberg MT, Weissberg RP, O’Brien MU, et al. Enhancing schoolbased prevention and youth development through coordinated social, emotional, and academic learning. Am Psychol. 2003;58(6-7):466-474.

27. Payton JW, Wardlaw DM, Graczyk PA, Bloodworth MR, Tompsett CJ, Weissberg RP. Social and emotional learning: a framework for promoting mental health and reducing risk behavior in children and youth. J Sch Health. 2000;70(5):179-185.

28. Sheldon SB. Linking school-family-community partnerships in urban elementary schools to student achievement on state tests. Urban Review. 2003;35(2):149-165.

29. Bryan J. Fostering educational resilience and achievement in urban schools through school-family-community partnerships. Professional School Counseling. 2005:219-227.

30. Birmaher B, Brent DA, Chiappetta L, Bridge J, Monga S, Baugher M. Psychometric properties of the Screen for Child Anxiety Related Emotional Disorders (SCARED): a replication study. J Am Acad Child Adolesc Psychiatry. 1999;38(10):1230-1236.

31. Schonert-Reichl KA, Oberle E, Lawlor MS, et al. Enhancing cognitive and social-emotional development through a simple-to-administer mindfulness-based school program for elementary school children: a randomized controlled trial. Dev Psychol. 2015;51(1):52-66.
32. Urbaniak GC, Plous S. Research Randomizer (Version 4.0) [Computer Software] Available from: http://www.randomizer.org/. 2013. Accessed June 22, 2017.

33. Bastiaansen D, Koot HM, Bongers IL, Varni JW, Verhulst FC. Measuring quality of life in children referred for psychiatric problems: psychometric properties of the PedsQL 4.0 generic core scales. Qual Life Res. 2004;13(2):489-495.

34. Bickman L, Athay MM, Riemer M, et al. Manual of the Peabody Treatment Battery. 2nd ed. 2010. Vanderbilt University, Nashville, TN, USA. Available from: https://peabody.vanderbilt.edu/docs/pdf/ ceci/ptpb_2nd_ed/PTPT_2010_Entire_Manual_UPDATE_31212.pdf. Accessed June 5, 2017.

35. Varni JW, Seid M, Rode CA. The PedsQL: measurement model for the pediatric quality of life inventory. Med Care. 1999;37(2):126-139.

36. Varni JW, Seid M, Kurtin PS. PedsQL 4.0: reliability and validity of the pediatric quality of life inventory version 4.0 generic core scales in healthy and patient populations. Med Care. 2001;39(8):800-812.

37. Moriarty DG, Zack MM, Kobau R. The centers for disease control and prevention's healthy days measures-population tracking of perceived physical and mental health over time. Health Qual Life Outcomes. 2003;1:37.

38. Burton P, Gurrin L, Sly P. Extending the simple linear regression model to account for correlated responses: an introduction to generalized estimating equations and multi-level mixed modelling. Stat Med. 1998;17(11):1261-1291.

39. Hanley JA, Negassa A, Edwardes MD, Forrester JE. Statistical analysis of correlated data using generalized estimating equations: an orientation. Am J Epidemiol. 2003;157(4):364-375.

40. Rotnitzky A, Jewell NP. Hypothesis testing of regression parameters in semiparametric generalized linear models for cluster correlated data. Biometrika. 1990;77(3):485-497.

41. Zhang H, Xia Y, Chen R, Gunzler D, Tang W, Tu X. Modeling longitudinal binomial responses: implications from two dueling paradigms. J Appl Stat. 2011;38(11):2373-2390.

42. Dariotis JK, Cluxton-Keller F, Mirabal-Beltran R, Gould LF, Greenberg MT, Mendelson T. "The program affects me 'Cause it gives away stress': urban students" qualitative perspectives on stress and a school-based mindful yoga intervention. Explore (NY). 2016;12(6): 443-450.

43. Dariotis JK, Mirabal-Beltran R, Cluxton-Keller F, Gould LF, Greenberg MT, Mendelson T. A qualitative evaluation of student learning and skills use in a school-based mindfulness and yoga program. Mindfulness (NY). 2016;7(1):76-89.

44. Hagins M, Haden SC, Daly LA. A randomized controlled trial on the effects of yoga on stress reactivity in 6th grade students. Evid Based Complement Alternat Med. 2013;2013:607134.

45. Hagen I, Nayar US. Yoga for children and young people's mental health and well-being: research review and reflections on the mental health potentials of yoga. Front Psychiatry. 2014;5:35
Psychology Research and Behavior Management

\section{Publish your work in this journal}

Psychology Research and Behavior Management is an international, peerreviewed, open access journal focusing on the science of psychology and its application in behavior management to develop improved outcomes in the clinical, educational, sports and business arenas. Specific topics covered in the journal include: Neuroscience, memory and decision making; Behavior modification and management; Clinical applications; Business and sports performance management; Social and developmental studies; Animal studies. The manuscript management system is completely online and includes a very quick and fair peer-review system, which is all easy to use. Visit http://www. dovepress.com/testimonials.php to read real quotes from published authors. 